\title{
Decadal soil carbon accumulation across Tibetan permafrost regions
}

Jinzhi Ding ${ }^{1,2}$, Leiyi Chen ${ }^{1}$, Chengjun $\mathrm{Ji}^{3}$, Gustaf Hugelius ${ }^{4,5}$, Yingnian $\mathrm{Li}^{6}$, Li Liu ${ }^{1,2}$, Shuqi Qin ${ }^{1,2}$, Beibei Zhang ${ }^{1}$, Guibiao Yang ${ }^{1,2}$, Fei Li $^{1,2}$, Kai Fang ${ }^{1,2}$, Yongliang Chen ${ }^{1}$, Yunfeng Peng ${ }^{1}$, Xia Zhao ${ }^{1}$, Honglin $\mathrm{He}^{7}$, Pete $\mathrm{Smith}^{8}$, Jingyun Fang ${ }^{1,3}$, and Yuanhe Yang $^{1,2 *}$

${ }^{1}$ State Key Laboratory of Vegetation and Environmental Change, Institute of Botany, Chinese Academy of Sciences, Beijing 100093, China

${ }^{2}$ University of Chinese Academy of Sciences, Beijing 100049, China

${ }^{3}$ Department of Ecology, College of Urban and Environmental Sciences, and Key Laboratory for Earth Surface Processes of the Ministry of Education, Peking University, Beijing 100871, China

${ }^{4}$ Department of Physical Geography, Stockholm University, Stockholm 10691, Sweden

${ }^{5}$ Department of Earth System Science, Stanford University, Stanford 94305 CA, USA

${ }^{6}$ Key Laboratory of Adaptation and Evolution of Plateau Biota, Northwest Institute of Plateau Biology, Chinese Academy of Sciences, Xining, Qinghai 810001, China

${ }^{7}$ Key Laboratory of Ecosystem Network Observation and Modeling, Institute of Geographic Sciences and Natural Resources Research, Chinese Academy of Sciences, Beijing 100101, China

${ }^{8}$ Institute of Biological and Environmental Sciences, University of Aberdeen, Aberdeen, AB24 3UU, UK

*Corresponding author: Dr. Yuanhe Yang, tel.: + 86 10-6283 6638, fax: + 86 10-6283 6632, E-mail: yhyang@ibcas.ac.cn 


\section{Supplementary discussion}

\section{Linking soil $\mathbf{C}$ accumulation to climate change}

We observed an overall increase in soil organic carbon (SOC) stock in the top $30 \mathrm{~cm}$ across the Tibetan permafrost regions. The soil $\mathrm{C}$ accumulation could be related to the significant increment in vegetation C-inputs to soils (Supplementary Fig. 3-4 and Supplementary Table 3), given the close relationship between vegetation growth (EVI-index) and $\operatorname{SOCD}\left(r^{2}=0.66, P<0.001\right)^{1}$. The increase in vegetation growth was further demonstrated as a climate-driven process. Firstly, climate changes (warmer and wetter climate, Supplementary Fig. 5) had contributed to the vegetation yield increment on the plateau over the past decade, as confirmed by both a site-level monitoring experiment ${ }^{2}$ and regional-scale model simulations $s^{3,4,5,6}$. At the site level (i.e. Haibei Alpine Meadow Ecosystem Research Station), increase in growing season temperature accounted for $41 \%$ of the increase in net primary production (NPP) over the period 2001-2011 in a typical alpine meadow on the north-eastern plateau ${ }^{2}$. At the regional scale, changes in temperature and precipitation on the Tibetan Plateau explained 34\% and 52\% of the increase in NPP from 1960 to 2009, respectively ${ }^{4}$. Secondly, China's national conservation policies could also stimulate vegetation growth, but with a lesser degree, because vegetation dynamics were reported to be driven by climate change rather than human activities in most areas (> 90\%) of the Tibetan Plateau ${ }^{7}$. Moreover, most of the sampling sites (> 90\%) had not experienced changes in land management practices during the intra-sampling period. In addition, the vegetation production had already increased since the 1980s, at least 
20 years ahead of the implementation of national conservation policies (Supplementary Fig. 6). These two aspects of evidences suggest the dominant role of climate change in driving the vegetation productivity increase and resultant soil $\mathrm{C}$ accumulation across Tibetan permafrost regions.

\section{Linking changes in soil bulk density to vegetation dynamics}

We observed a reduction of soil bulk density (BD) in subsurface layers of the alpine meadow, which may be driven by enhanced vegetation productivity. Generally, the changes in BD depend on both organic matter content and soil porosity ${ }^{8}$. Enhanced vegetation productivity would elevate the proportion of organic matter and/or aggregation, resulting in an overall decrease in $\mathrm{BD}^{9}$, which was confirmed by a significant negative correlation between change rates in SOC concentration (SOCC) and BD $\left(r^{2}=0.27, P<0.001\right.$; Supplementary Fig. 10$)$. Also, more root penetration as a result of enhanced root production and greater number of soil animals, such as earthworms supported by increased organic matter could create more pore space in the soils ${ }^{10}$, and resulted in a decreased BD.

Although significant increases in vegetation productivity occurred in both alpine steppe and alpine meadow, significant decrease of BD was only observed in meadow soils. The difference in BD changes between the two grassland types may be associated with higher rates of change of vegetation inputs in the alpine meadow. Specifically, it had been proposed that plant growth of the alpine meadow would 
benefit more from the significant warming during the past decade, due to reduced drought stress from increased precipitation (Supplementary Fig. 11) ${ }^{11}$. This hypothesis was confirmed by a significant and positive relationship between increased rate of EVI $(\triangle \mathrm{EVI})$ and mean annual precipitation (MAP), and a higher increase rate of EVI in the alpine meadow than in the alpine steppe over the study period (Supplementary Fig. 11). In addition to the greater increase in EVI, larger absoute amount and proportion of root biomass in the upper $30 \mathrm{~cm}$ of soils were also observed in alpine meadows compared to alpine steppes (Supplementary Fig. 12). If we assume a relatively constant ratio between above- and below- ground biomass ${ }^{12}$, the alpine meadow would have experienced more increase in root biomass in upper $30 \mathrm{~cm}$. Taken together, both higher above- and below- ground biomass changes would contribute to larger SOCC accumulation (Fig. 3) and more pore-space from root-penetration and bioturbation in meadow soils $\mathrm{s}^{8,9,10}$, leading to larger reductions of BD in meadow soils. 
Supplementary Table 1 | Comparisons of mean bulk density $(\mathrm{BD} \pm \mathrm{SE}$ ), soil organic carbon concentration (SOCC \pm SE), and soil organic carbon density (SOCD \pm SE) across 103 resampling sites between the 2000s and the 2010s.

\begin{tabular}{|c|c|c|c|c|c|c|}
\hline \multirow{2}{*}{ Soil depth $(\mathrm{cm})$} & \multicolumn{2}{|c|}{$\mathrm{BD}\left(\mathrm{g} \mathrm{cm}^{-3}\right)$} & \multicolumn{2}{|c|}{$\mathrm{SOCC}\left(\mathrm{g} \mathrm{kg}^{-1}\right)$} & \multicolumn{2}{|c|}{$\operatorname{SOCD}\left(\mathrm{kg} \mathrm{C} \mathrm{m}^{-2}\right)$} \\
\hline & $2000 \mathrm{~s}$ & $2010 s$ & $2000 \mathrm{~s}$ & 2010s & $2000 \mathrm{~s}$ & $2010 \mathrm{~s}$ \\
\hline \multicolumn{7}{|l|}{ Alpine steppe } \\
\hline $0-10$ & $1.36 \pm 0.02$ & $1.36 \pm 0.01$ & $10.89 \pm 1.10$ & $10.11 \pm 0.68$ & $1.16 \pm 0.08$ & $1.15 \pm 0.07$ \\
\hline $10-20$ & $1.38 \pm 0.02$ & $1.41 \pm 0.01$ & $8.26 \pm 0.45$ & $9.21 \pm 0.46$ & $0.93 \pm 0.05$ & $1.07 \pm 0.05$ \\
\hline $20-30$ & $1.44 \pm 0.02$ & $1.43 \pm 0.02$ & $5.93 \pm 0.38$ & $7.00 \pm 0.42$ & $0.66 \pm 0.04$ & $0.79 \pm 0.05$ \\
\hline \multicolumn{7}{|l|}{ Alpine meadow } \\
\hline $0-10$ & $0.99 \pm 0.02$ & $1.00 \pm 0.02$ & $42.43 \pm 2.30$ & $39.91 \pm 2.29$ & $3.52 \pm 0.14$ & $3.33 \pm 0.15$ \\
\hline $10-20$ & $1.21 \pm 0.02$ & $1.16 \pm 0.02$ & $22.49 \pm 1.20$ & $27.58 \pm 1.68$ & $2.25 \pm 0.11$ & $2.60 \pm 0.14$ \\
\hline $20-30$ & $1.31 \pm 0.02$ & $1.28 \pm 0.02$ & $13.61 \pm 0.98$ & $16.30 \pm 1.17$ & $1.43 \pm 0.09$ & $1.66 \pm 0.10$ \\
\hline \multicolumn{7}{|l|}{ All grasslands } \\
\hline $0-10$ & $1.22 \pm 0.02$ & $1.22 \pm 0.02$ & $22.61 \pm 1.40$ & $21.19 \pm 1.26$ & $2.04 \pm 0.10$ & $1.96 \pm 0.09$ \\
\hline $10-20$ & $1.32 \pm 0.01$ & $1.31 \pm 0.01$ & $13.74 \pm 0.67$ & $16.29 \pm 0.87$ & $1.44 \pm 0.06$ & $1.66 \pm 0.07$ \\
\hline $20-30$ & $1.39 \pm 0.02$ & $1.37 \pm 0.01$ & $8.87 \pm 0.50$ & $10.55 \pm 0.58$ & $0.95 \pm 0.05$ & $1.12 \pm 0.05$ \\
\hline
\end{tabular}


Supplementary Table 2 | Statistical parameters of annual change rates of soil organic carbon density (SOCD), bulk density (BD), and soil organic carbon concentration (SOCC) from the 2000s to the 2010s by grassland type and soil depth, as derived from the linear mixed models.

\begin{tabular}{lcccccccc}
\hline \multirow{2}{*}{ Response variable } & \multicolumn{2}{c}{$0-10 \mathrm{~cm}$} & \multicolumn{2}{c}{$10-20 \mathrm{~cm}$} & \multicolumn{2}{c}{$20-30 \mathrm{~cm}$} & \multicolumn{2}{c}{$0-30 \mathrm{~cm}$} \\
\cline { 2 - 9 } & $\chi^{2}$ & $P$ & $\chi^{2}$ & $P$ & $\chi^{2}$ & $P$ & $\chi^{2}$ & $P$ \\
\hline Alpine steppe & & & & & & & & \\
SOCD & 0.02 & 0.89 & 17.26 & $* * *$ & 16.76 & $* * *$ & 11.91 & $* * *$ \\
BD & 0.04 & 0.85 & 2.80 & 0.09 & 0.75 & 0.39 & & \\
SOCC & 0.69 & 0.41 & 14.51 & $* * *$ & 17.22 & $* * *$ & & \\
\hline Alpine meadow & & & & & & & & \\
SOCD & 1.63 & 0.16 & 12.88 & $* * *$ & 8.73 & $* *$ & 8.02 & $* *$ \\
BD & 0.00 & 1.00 & 6.51 & $*$ & 5.70 & $*$ & & \\
SOCC & 1.80 & 0.18 & 21.60 & $* * *$ & 14.98 & $* * *$ & & \\
\hline All grasslands & & & & & & & & \\
SOCD & 2.59 & 0.11 & 29.32 & $* * *$ & 25.40 & $* * *$ & 26.95 & $* * *$ \\
BD & 0.10 & 0.75 & 0.07 & 0.79 & 3.91 & 0.05 & & \\
SOCC & 0.00 & 1.00 & 27.77 & $* * *$ & 29.19 & $* * *$ & & \\
\hline$* * *$ represents $P<0.001 ; * *$ & represents $0.001<P<0.01 ; *$ represents $0.01<P<0.05$.
\end{tabular}


Supplementary Table 3 | Summary of temporal dynamics of net primary production (NPP) across alpine ecosystems on the Tibetan Plateau in various modelling studies.

\begin{tabular}{cccc}
\hline Model & Period & Relative increasing rate $(\%)$ & Reference \\
\hline CASA & $1982-1999$ & $1.00 \%$ & Piao et al. $2002^{13}$ \\
ORCHIDEE & $1961-2009$ & $1.02 \%$ & Piao et al. $2012^{4}$ \\
CASA & $1982-2011$ & $0.84 \%$ & Chen et al. $2014^{14}$ \\
CASA & $1982-2009$ & $0.46 \%$ & Zhang et al. $2014^{15}$ \\
TEM & $1979-2011$ & $0.26 \%$ & Jin et al. $2015^{16}$ \\
\hline
\end{tabular}

CASA: Carnegie-Ames-Stanford Approach; ORCHIDEE: Organizing Carbon and Hydrology In Dynamic Ecosystems; TEM: Terrestrial Ecosystem Model. 


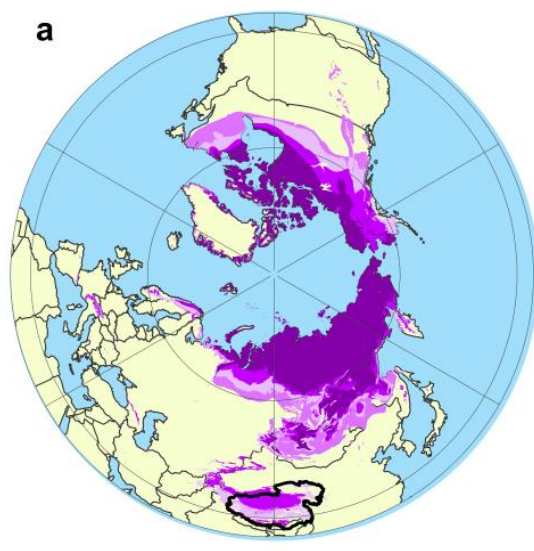

Premafrost

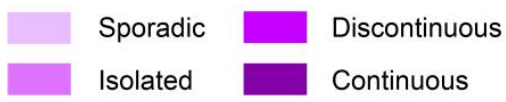

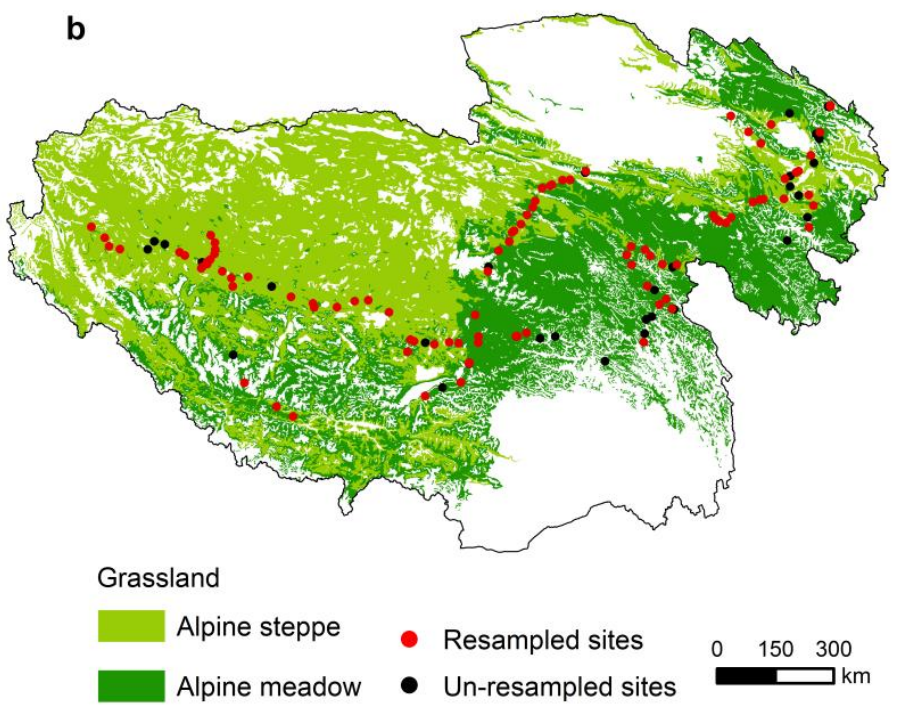
Supplementary Figure 1 | (a) Circumpolar map of permafrost ${ }^{17}$, (b) spatial
distributions of resampling sites and major grassland types on the Tibetan Plateau. The vegetation map was obtained from China's vegetation atlas with a scale of 1: $1000000^{18}$. Both red and black dots represent the sampling sites investigated during the 2001-2004. Of these, red dots represent well-matched resampling sites during the 2013-2014; black dots represent sites which could not be resampled due to practical constraints such as road rebuilding and human disturbance. 
a

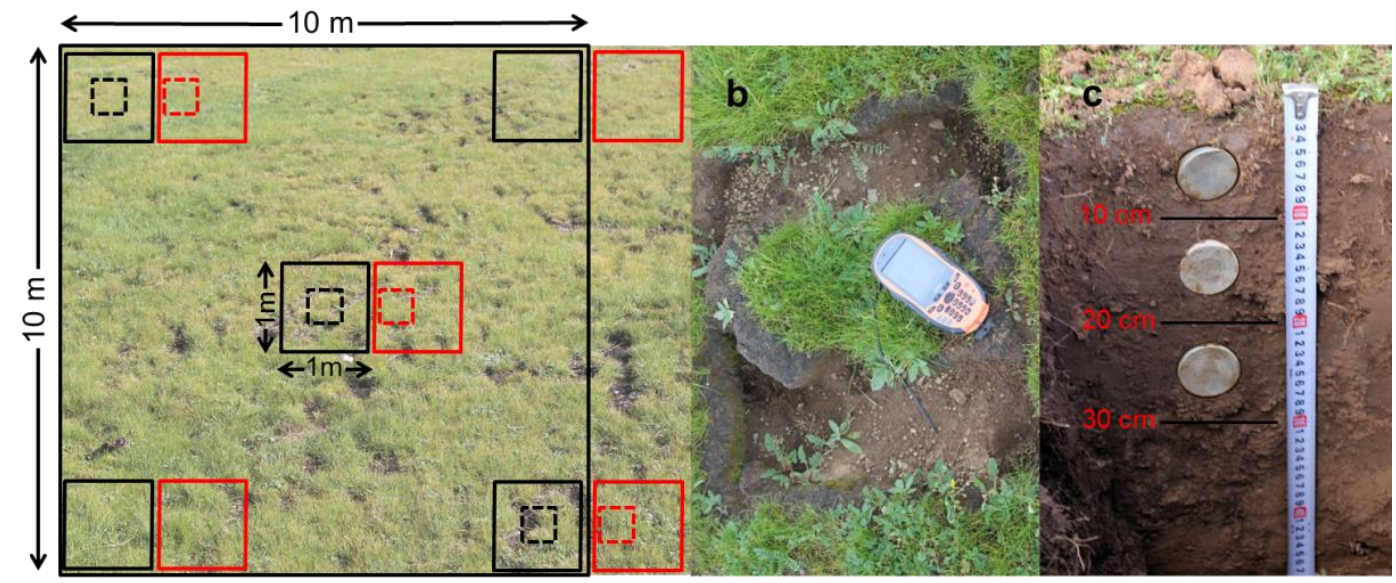

Supplementary Figure 2 | The picture of sampling design (a), and photos of the original soil pit during the 2000s (b) and resampling soil pit during the 2010s (c). The soil samples were collected following exactly the same sampling scheme during the two sampling periods. Specifically, five $1 \times 1 \mathrm{~m}^{2}$ quadrats (represented by solid squares) located at each corner and the centre of a $10 \times 10 \mathrm{~m}^{2}$ plot was set up for each site. After the harvest of aboveground biomass, three pits (represented by dashed squares) were excavated within three quadrats along the diagonal line of the plot. The resampling soil pits (red dashed squares) were located adjacent to the original soil pits (black dashed squares). A ruler was then put inside along the profile, steel cylinders with a fixed volume size of $100 \mathrm{~cm}^{3}$ were then pushed into the soil profile, with the cylinder centre aiming at the centre depth of each target soil layer (i.e. 5, 15, and 25 $\mathrm{cm}$ depth). Soil samples were collected from the top $10 \mathrm{~cm}$ depth (surface soils), and subsequently for the soil layers of 10-20 and 20-30 cm (subsurface soils). 


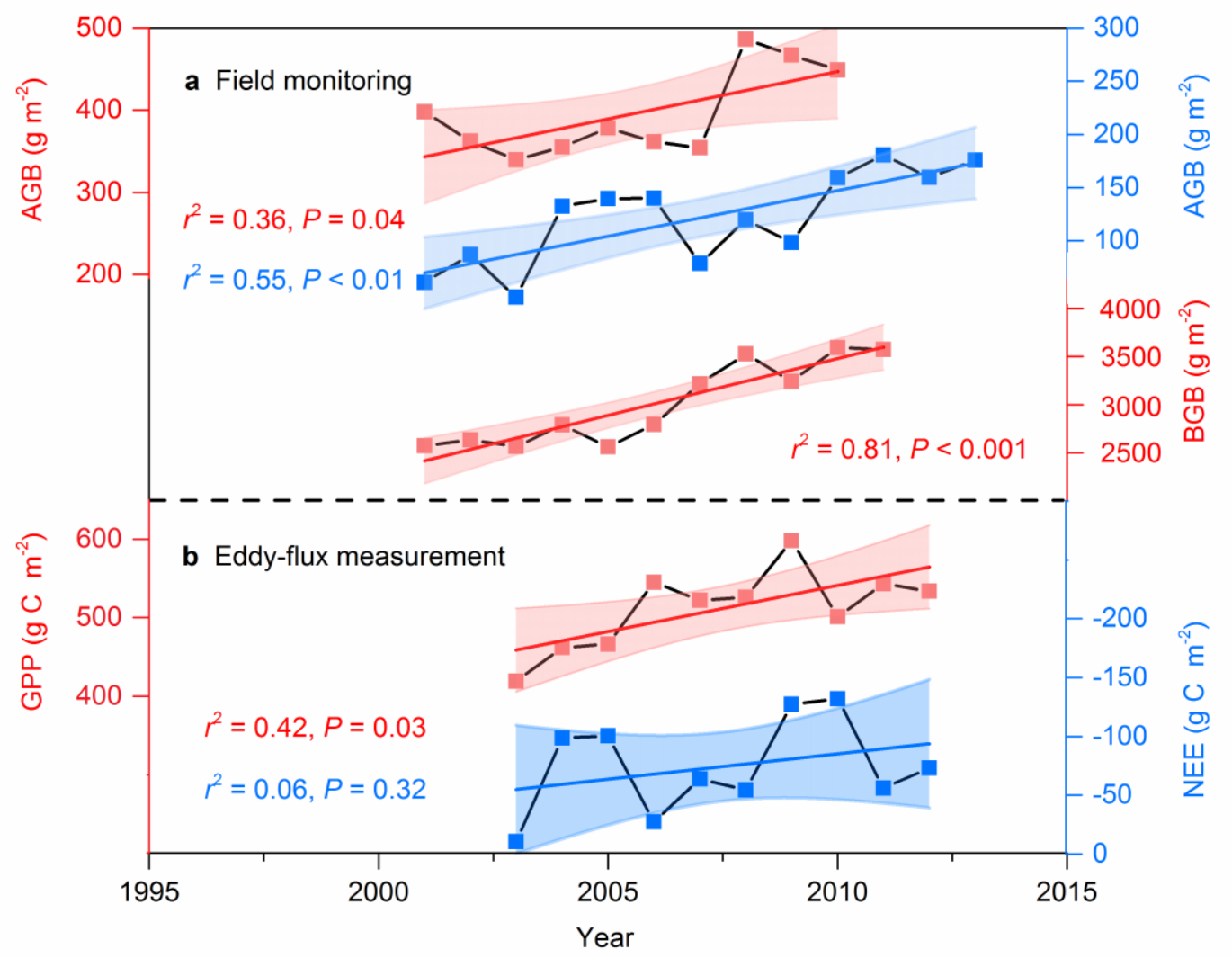

Supplementary Figure 3 | Inter-annual variations of (a) aboveground biomass (AGB), belowground biomass (BGB) from two long-term field monitoring stations and (b) gross primary productivity (GPP) and net ecosystem exchange (NEE) based on the Haibei eddy-flux tower. The field monitoring stations include Haibei Alpine Meadow Ecosystem Research Station (coloured in red) ${ }^{19}$ and Xinghai Alpine Steppe Ecosystem Research Station (coloured in blue; Related data were provided by Prof. Yingnian Li from Northwest Institute of Plateau Biology, Chinese Academy of Sciences). The significantly increased AGB, BGB and GPP suggest the enhanced vegetation $C$ inputs and the negative values of NEE indicate that the monitored ecosystem had been a continuous ecosystem $C$ sink over the past decade ${ }^{20}$. Of these, the relative increases of AGB and BGB (relative to mean biomass over the monitoring period) for the Haibei Alpine Meadow were 2.9 and $3.9 \% \mathrm{yr}^{-1}$. Note that shaded area denotes $95 \%$ confidence intervals of the linear fittings. 


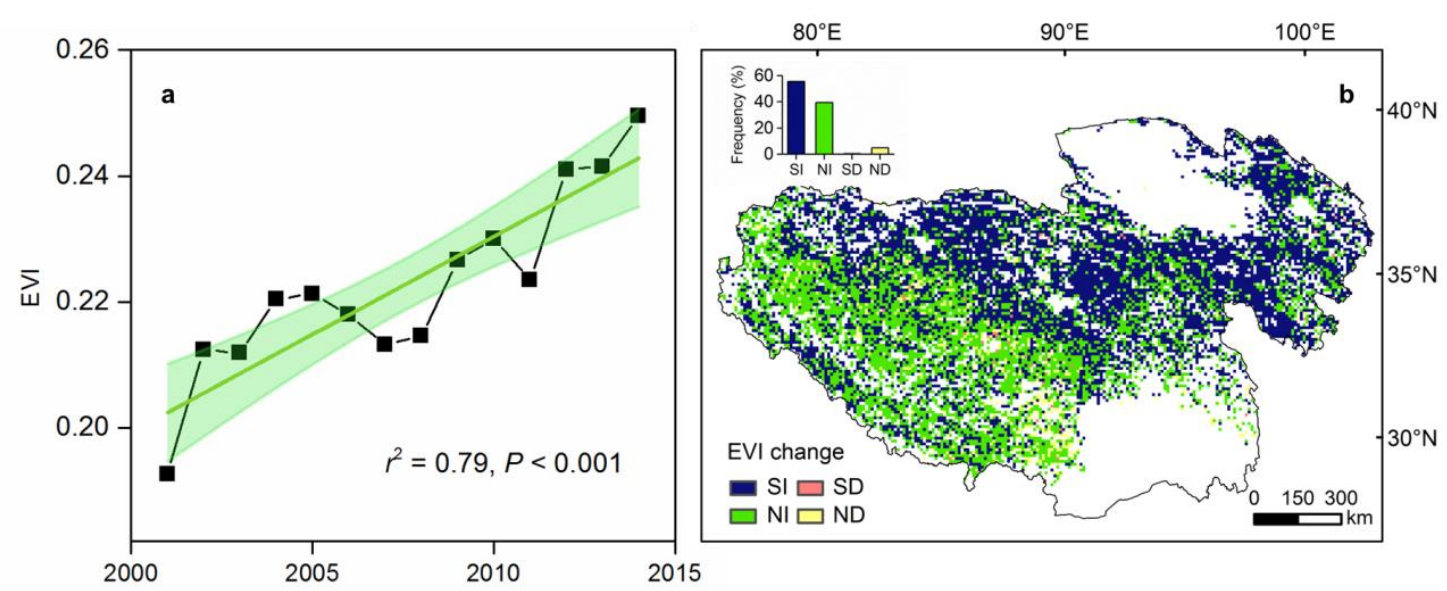

Supplementary Figure 4 | Trends in Enhanced Vegetation Index (EVI) across the 103 resampling sites (a) and Tibetan alpine grasslands (b) from 2001 to 2014. Bar charts in upper-left corner show the percentages of significantly increased (SI), non-significantly increased (NI), significantly decreased (SD) and non-significantly decreased (ND) EVI. Note that shaded area represents the 95\% confidence interval of fitting line. 


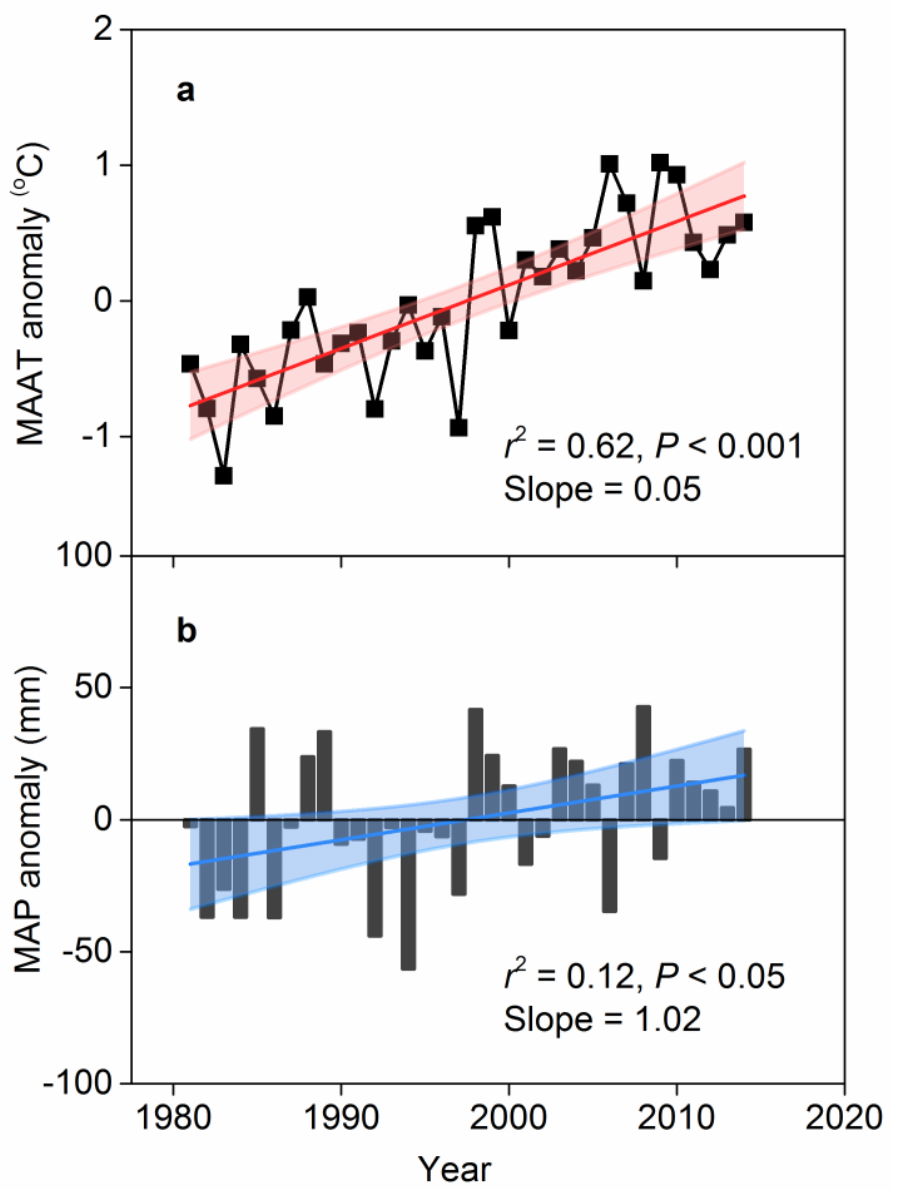

Supplementary Figure 5 | Anomalies of mean annual air temperature (MAAT) and mean annual precipitation (MAP) from 57 meteorological stations on the Tibetan Plateau from 1981 to 2014. The climate records of the stations on the plateau were obtained from the China Meteorological Administration (http://data.cma.cn/). Shaded area represents 95\% confidence intervals of the linear fittings. 


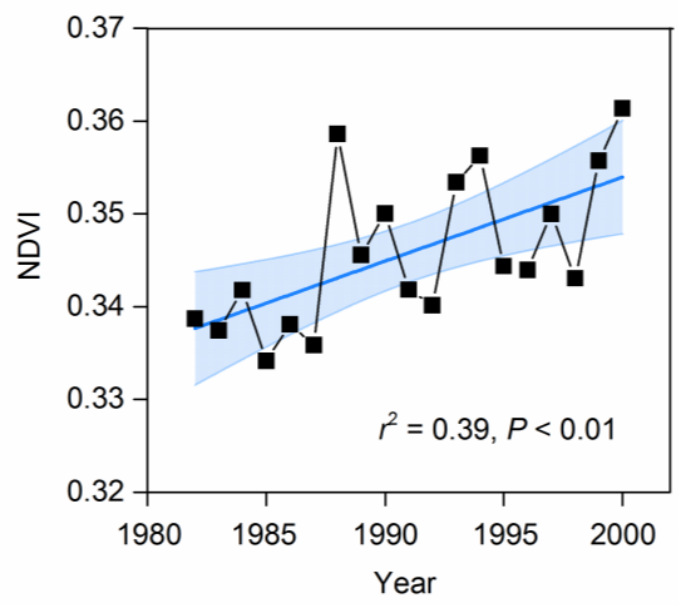

Supplementary Figure 6 | Inter-annual variations of Normalized Difference Vegetation Index (NDVI) from 1982 to 2000 across 103 resampling sites on the Tibetan Plateau. Shaded area denotes the 95\% confidence interval of the linear fitting. 


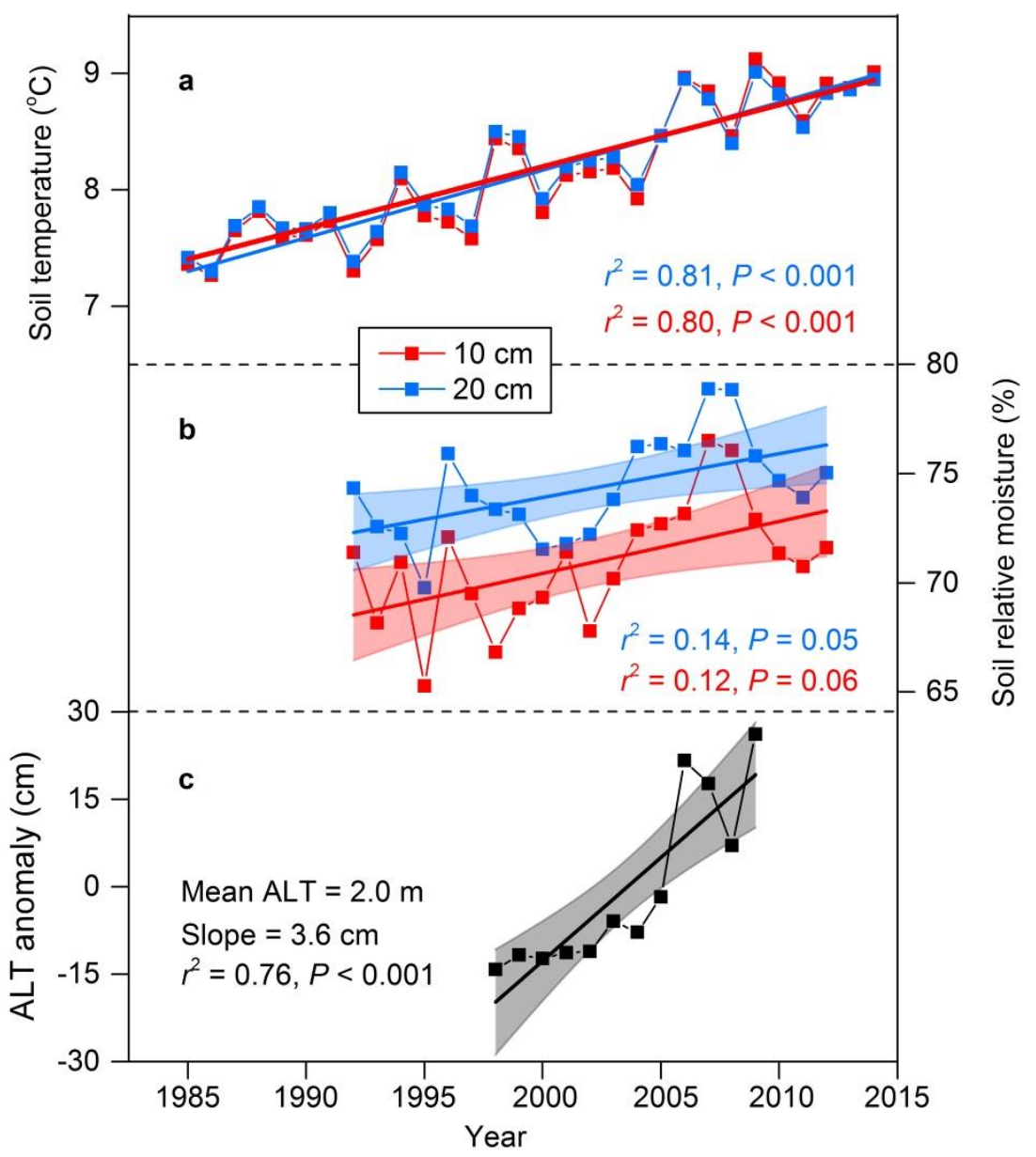

Supplementary Figure 7 | Inter-annual variations of (a) annual mean soil temperature (b), annual mean soil relative moisture, and (c) active layer thickness (ALT) anomaly on the Tibetan Plateau during past few decades. The soil temperature data (from 62 stations) and soil relative moisture data (from 20 stations) were obtained from the China Meteorological Data Service Center (http://data.cma.cn/en). The active layer thickness (ALT) data of 6 long-term in situ monitoring sites were obtained from the Circumpolar Active Layer Monitoring Network (https://www2.gwu.edu/ calm/data/north.html). The shaded areas denote $95 \%$ confidence intervals of the linear fittings. 


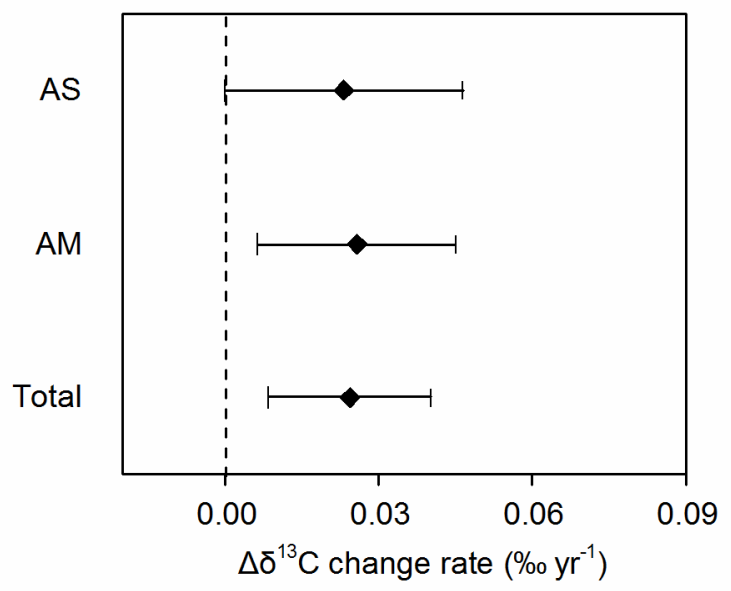

Supplementary Figure $8 \mid$ Mean change rate in $\Delta \delta^{13} \mathrm{C}$ (i.e. the difference of $\delta^{13} \mathrm{C}$ between surface soil and aboveground source plants, which has been frequently used to reflect isotopic fraction during microbial decomposition ${ }^{21,22,23}$ ) from the 2000s to 2010s across Tibetan alpine permafrost regions, as derived from linear mixed models. Error bars indicate 95\% confidence intervals (CI). AS, alpine steppe; $\mathrm{AM}$, alpine meadow. The significant increases of $\Delta \delta^{13} \mathrm{C}$ indicate an enhanced SOM decomposition in the surface soils, since lower $\Delta \delta^{13} \mathrm{C}$ values are connected to less degraded material, while higher $\Delta \delta^{13} \mathrm{C}$ values reflect greater decomposition ${ }^{24,25,26}$. 


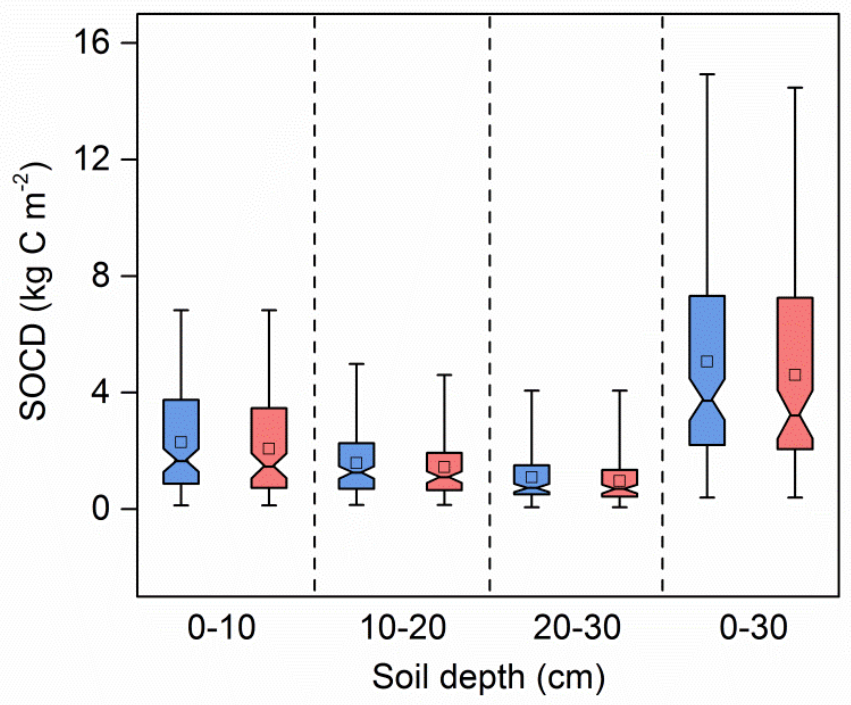

Supplementary Figure 9 | Comparison of soil organic carbon density (SOCD) during the 2000s between all 135 sites (coloured in blue) and 103 sites (coloured in red) which was resampled during the $2010 \mathrm{~s}$ across Tibetan alpine permafrost regions. The whiskers illustrate the minimum and maximum value, and the box ends indicate the $25^{\text {th }}$ and the $75^{\text {th }}$ quartiles. The horizontal lines and open squares inside each box represent median and mean values, respectively. The notches indicate the $95 \%$ confidence intervals. 


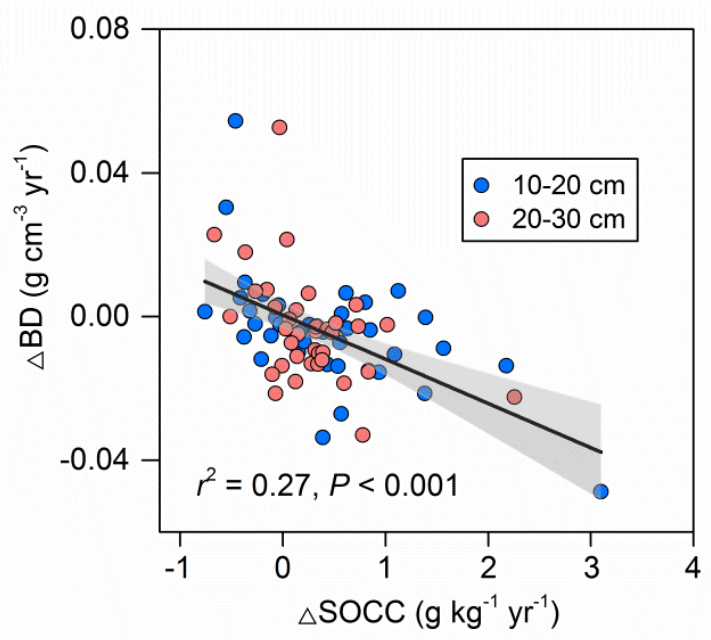

Supplementary Figure 10 | Relationship between change rates of soil bulk density $(\triangle B D)$ and soil organic carbon concentration ( $\triangle S O C C)$ at subsurface soil layers across Tibetan alpine meadows from the 2000s to 2010s. The shaded area denotes $95 \%$ confidence interval of the linear fitting. 


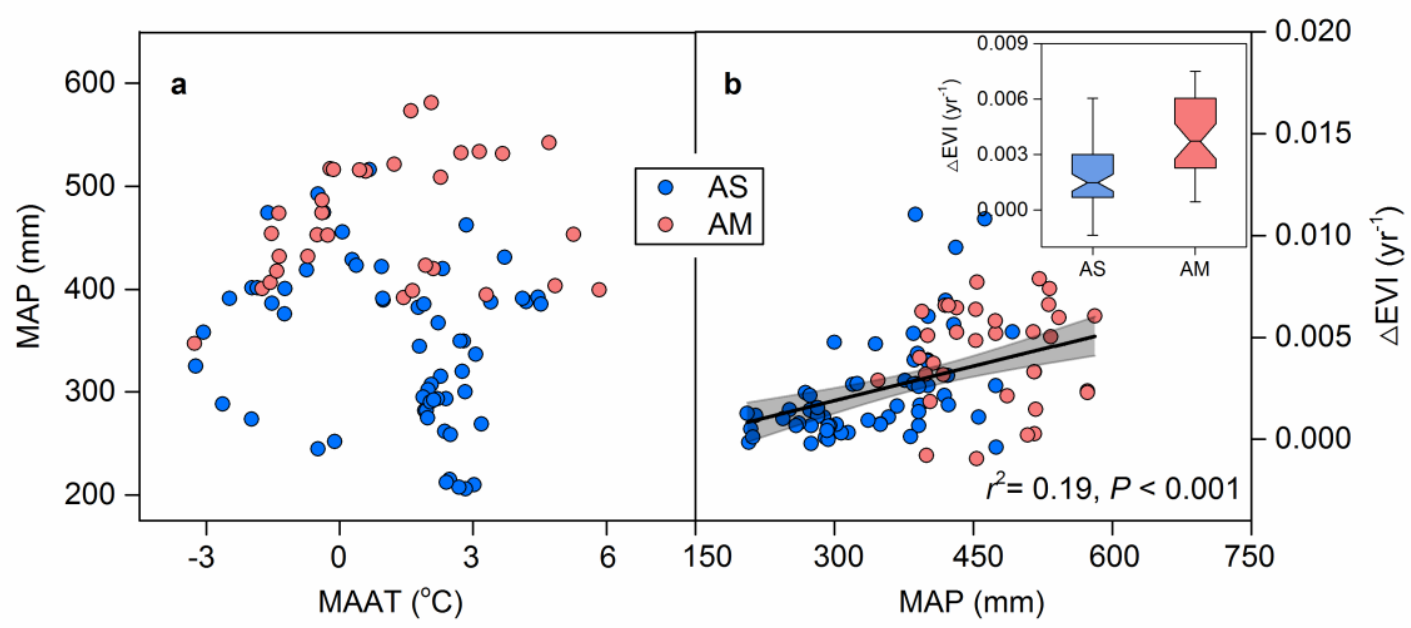

Supplementary Figure 11 | (a) The climate conditions for the 103 resampling sites across Tibetan alpine permafrost regions. (b) Relationship between EVI change rate ( $\triangle E V I)$ and mean annual precipitation (MAP) for the 103 resampling sites. Mean annual precipitation is higher in the alpine meadow (AM) than in the alpine steppe (AS), but no significant difference of mean annual air temperature (MAAT) between the two grassland types. Insert represents that enhanced vegetation production occurred in both the alpine steppe and alpine meadow, but the increase rate was larger in the alpine meadow than that in the alpine steppe. Note that the shaded area denotes $95 \%$ confidence interval of the linear fitting. 


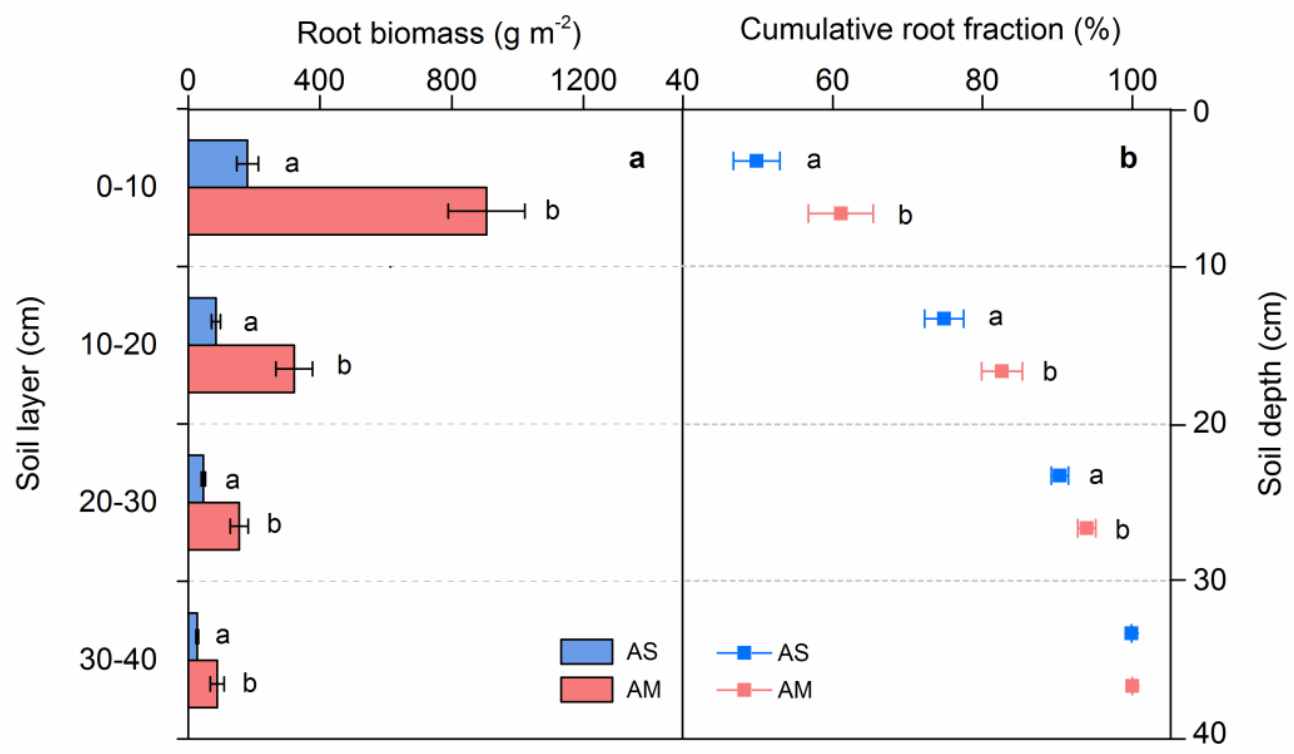

Supplementary Figure 12 | (a) Root biomass and (b) cumulative root fraction (mean \pm SE) between the alpine steppe (AS) and alpine meadow (AM) at different soil depths. Mean values with different letters $(a, b)$ indicate significant differences between the two grassland types at each depth interval (Kruskal-Wallis test, $P<0.05)$. Related data were derived from an investigation across the Tibetan alpine permafrost regions in $2005^{27}$. 


\section{Supplementary References}

1. Yang, Y. et al. Storage, patterns and controls of soil organic carbon in the Tibetan grasslands. Glob. Change Biol. 14, 1592-1599 (2008).

2. Li, H., Li, Y., Zhang, F., Liu, X., Wu, Q. \& Mao, S. Variations of production and water use efficiency of the vegetation in alpine meadow. Journal of Glaciology and Geocryology 35, 475-482 (2013).

3. Zhuang, Q. et al. Carbon dynamics of terrestrial ecosystems on the Tibetan Plateau during the 20th century: an analysis with a process-based biogeochemical model. Glob. Ecol. Biogeogr. 19, 649-662 (2010).

4. Piao, S. et al. Impacts of climate and $\mathrm{CO}_{2}$ changes on the vegetation growth and carbon balance of Qinghai-Tibetan grasslands over the past five decades. Glob. Planet. Change 98-99, 73-80 (2012).

5. Piao, S.L., Fang, J.Y. \& He, J.S. Variations in vegetation net primary production in the Qinghai-Xizang Plateau, China, from 1982 to 1999. Clim. Change 74, 253-267 (2006).

6. Yuan, Q. et al. Modeling net primary productivity of the terrestrial ecosystem in China from 1961 to 2005. J. Geogr. Sci. 24, 3-17 (2014).

7. Huang, K. et al. The influences of climate change and human Activities on vegetation dynamics in the Qinghai-Tibet Plateau. Remote Sensing 8, 876 (2016).

8. Rowell, D.L. Soil Science: Methods \& Applications (Routledge, New York, 2014).

9. Périé, C. \& Ouimet, R. Organic carbon, organic matter and bulk density relationships in boreal forest soils. Can. J. Soil Sci. 88, 315-325 (2008).

10. Shipitalo, M. \& Le Bayon, R.-C. Quantifying the effects of earthworms on soil aggregation and porosity. Earthworm Ecology (CRC Press, Florida, 2004).

11. Li, X. et al. Root biomass distribution in alpine ecosystems of the northern Tibetan Plateau. Environ. Earth Sci. 64, 1911-1919 (2011).

12. Yang, Y., Fang, J., Ma, W., Guo, D. \& Mohammat, A. Large-scale pattern of 
biomass partitioning across China's grasslands. Glob. Ecol. Biogeogr. 19, 268-277 (2010).

13. Piao, S. \& Fang, J. Terrestrial net primary production and its spatio-temporal patterns in Qinghai-Xizang Plateau, China during 1982-1999. Journal of Natural Resources 17, 373-380 (2002).

14. Chen, B. et al. The impact of climate change and anthropogenic activities on alpine grassland over the Qinghai-Tibet Plateau. Agr. Forest Meteorol. 189190, $11-18$ (2014).

15. Zhang, Y. et al. Spatial and temporal variability in the net primary production of alpine grassland on the Tibetan Plateau since 1982. J. Geogr. Sci. 24, 269-287 (2014).

16. Jin, Z., Zhuang, Q., He, J.-S., Zhu, X. \& Song, W. Net exchanges of methane and carbon dioxide on the Qinghai-Tibetan Plateau from 1979 to 2100. Environ. Res. Lett. 10, 085007 (2015).

17. Brown, J., Ferrians, O.J., Jr., Heginbottom, J.A. \& Melnikov, E.S. Circum-arctic map of permafrost and ground ice conditions. (Boulder, CO: National Snow and Ice Data Center. Digital media.; 1998).

18. Chinese Academy of Sciences. Vegetation Atlas of China. (Science Press: Beijing, 2001).

19. Li, H. et al. Interannual variations of production and water use efficiency of the vegetation in alpine meadow. Journal of Glaciology and Geocryology 35, 475-482 (2013).

20. Li, H. et al. Seasonal and inter-annual variations in $\mathrm{CO}_{2}$ fluxes over 10 years in an alpine shrubland on the Qinghai-Tibetan Plateau, China. Agr. Forest Meteorol. 228-229, 95-103 (2016).

21. Garten, C.T., Cooper, L.W., Post, W.M. \& Hanson, P.J. Climate controls on forest soil C isotope ratios in the Southern Appalachian Mountains. Ecology 81, 1108-1119 (2000).

22. Wynn, J.G., Harden, J.W. \& Fries, T.L. Stable carbon isotope depth profiles and soil organic carbon dynamics in the lower Mississippi Basin. Geoderma 
131, 89-109 (2006).

23. Bird, M.I., Chivas, A.R. \& Head, J. A latitudinal gradient in carbon turnover times in forest soils. Nature 381, 143-146 (1996).

24. Gundelwein, A. et al. Carbon in tundra soils in the Lake Labaz region of arctic Siberia. Eur. J. Soil. Sci. 58, 1164-1174 (2007).

25. Wang, S. et al. Patterns of SOC and soil ${ }^{13} \mathrm{C}$ and their relations to climatic factors and soil characteristics on the Qinghai-Tibetan Plateau. Plant Soil 363, 243-255 (2013).

26. Guillaume, T., Damris, M. \& Kuzyakov, Y. Losses of soil carbon by converting tropical forest to plantations: erosion and decomposition estimated by $\delta^{13}$ C. Glob. Change Biol. 21, 3548-3560 (2015).

27. Yang, Y., Fang, J., Ji, C. \& Han, W. Above- and belowground biomass allocation in Tibetan grasslands. J. Veg. Sci. 20, 177-184 (2009). 